\title{
Surgical and Percutaneous Revascularization Outcomes based on SYNTAX I, II, and Residual Scores. A Long-Term follow-up Study.
}

Eduardo Bello Martins

Instituto do Coracao

Whady Hueb ( $\square$ mass@incor.usp.br)

Heart Institute (InCor) University of Sao Paulo https://orcid.org/0000-0002-3166-6054

David L Brown

Washington University School of Medicine in Saint Louis: Washington University in St Louis School of Medicine

Thiago Luis Scudeler Instituto do Coração: Instituto do Coracao

Eduardo Gomes Lima Instituto do Coração: Instituto do Coracao

Paulo Cury Rezende

Instituto do Coração: Instituto do Coracao

\section{Paulo Rogério Soares}

Instituto do Coração: Instituto do Coracao

Cibele Larrosa Garzillo

Instituto do Coração: Instituto do Coracao

Jaime Paula Pessoa Linhares Filho

Instituto do Coração: Instituto do Coracao

Daniel Valente Batista

Instituto do Coração: Instituto do Coracao

Jose Antonio Franchini Ramires

Instituto do Coração: Instituto do Coracao

Roberto Kalil Filho

Instituto do Coração: Instituto do Coracao

Research article

Keywords: Coronary artery disease, Coronary artery bypass grafting, Coronary angiography, Prognosis

Posted Date: May 7th, 2021 
DOI: https://doi.org/10.21203/rs.3.rs-472166/v1

License: (c) (1) This work is licensed under a Creative Commons Attribution 4.0 International License. Read Full License 


\section{Abstract}

\section{Background}

The objective of this study was to evaluate the association of SYNTAX scores I, II, and residual with cardiovascular outcomes of patients undergoing coronary artery bypass grafting (CABG) or percutaneous coronary intervention $(\mathrm{PCl})$ and compare both procedures in a long-term follow-up.

Methods

This is a retrospective single-center study from the MASS registry at the Heart Institute of the University of São Paulo, Brazil in which 969 patients with stable coronary artery disease undergoing CABG (559) or PCl (410) were included. Clinical endpoints were the first occurrence of a composite of overall death, myocardial infarction (MI), stroke, or repeat revascularization (MACCE) and the total occurrence of each component of MACCE.

Results

In the CABG sample, SSI had a median of 23 (IQR:17-29.5), median SSII of 25.4 (IQR:19.2-32.8), and median rSS of 2 (IQR:0-6.5); in PCI SSI had a median of 14 (IQR:10-19.1), median SSII of 28.7 (IQR:2334.2), and median rSS of 4.7 (IQR:0-9). Total of 174 events were documented and CABG patients had a lower rate of MACCE (15.6\% versus 21.2\%; adjusted HR: 1.98; 95\% Cl, 1.13-3.47; $P=.016)$ and repeat revascularization (3.8\% versus $11.5 \%$; adjusted HR: $4.35 ; \mathrm{Cl} 95 \%: 1.74-10.85 ; P=.002$ ) compared with $\mathrm{PCl}$. No SYNTAX score tertile found a difference in death rate between procedures. In a multivariate analysis, the rSS was an independent predictor for MACCE (HR=1.04; 95\% Cl, 1.01-1.06; $P=.001)$. Regarding death, the only independent predictors were ejection fraction and renal function.

\section{Conclusion}

Surgical revascularization resulted in a more complete revascularization and lower rates of major cardiac or cerebrovascular events in a long-term follow-up. Also, grading the incompleteness of revascularization through the residual SYNTAX score identified a higher event rate, suggesting that complete revascularization is associated with a better prognosis.

\section{Background}

Prognostic scores are frequently used in clinical practice to assist in the prediction of adverse cardiovascular events and to improve the management of patients with stable coronary artery disease (CAD). Yet, mortality in patients with stable CAD is similar regardless of the therapeutic strategy, and no score to date has proved useful in the selection of patients to reduce mortality in stable CAD.

Advances in the analysis of the anatomical characteristics of CAD enabled the development of the SYNTAX I score (SSI). ${ }^{1} \mathrm{SSI}$ allowed a single tool in assessing the atherosclerotic plaques according to 
their location, myocardial area at risk, and number and complexity of lesions. Also, its information would help in the choice of the best revascularization procedure as shown in the SYNTAX trial. ${ }^{2}$

In populations undergoing percutaneous coronary intervention (PCI), some studies have already found an association of SSI with events, the vast majority of which were in a short- or medium-term follow-up. ${ }^{3-5}$ Nevertheless, the prognostic value of SSI in populations undergoing coronary artery bypass grafting $(\mathrm{CABG})$ had inconsistent results in previous studies. ${ }^{4,6-11}$

The lack of clinical variables in the SSI led to the development of SYNTAX II (SSII), which identified independent predictors of mortality from the original population included in the SYNTAX study. ${ }^{12}$ The external validation of this score in a large registry of patients with CAD obtained a good calibration. ${ }^{12}$

Another limitation of SSI is its inability to analyze revascularization procedures for completeness because the incompleteness of revascularization is associated with a worse prognosis. ${ }^{13}$ To solve this issue, the residual SYNTAX score (rSS) was developed. This score better quantifies the completeness of revascularization by removing from the SSI points of properly treated lesions and was found to be an independent predictor of events after $\mathrm{PCl}^{14}$ In the surgical population, the long-term impact of rSS is still unknown.

Considering the scarcity of studies that simultaneously analyze the 3 scores in long-term follow-up and the controversial prognostic value of SYNTAX I and rSS in CABG, this study aimed to assess the prognostic value of all 3 of these scores in revascularization procedures.

\section{Methods}

This is a retrospective study based on a database from "The Medicine, Angioplasty or Surgery Study" (MASS) registry. Data were extracted from medical records of patients with stable CAD undergoing CABG or PCl at the Heart Institute of the University of São Paulo.

All groups were treated with medications, such as antiplatelet, anti-hypertensives, lipid-lowering, and antidiabetic drugs required to achieve adequate values of blood pressure and lipid and glycemic levels recommended by guidelines.

All patients had regular clinical follow-up every 6 months and, if necessary, additional visits were scheduled. Subjects in the PCl group received bare-metal stents (BMS) or drug-eluting stents (DES) as available. $\mathrm{PCl}$ was performed according to a standard protocol that included administration of aspirin and a thienopyridine agent before the start of the procedure and for a minimum duration of dual antiplatelet therapy of 1 month, up to 12 months, according to the type of stent used. Besides that, complete anatomic revascularization was recommended as the main goal.

For patients undergoing $C A B G$, the use of the left internal thoracic artery (LIMA) as the first-choice conduit for the LAD and, also, complete anatomical revascularization was encouraged. The use of cardiac 
extracorporeal circulation was defined at the discretion of the surgical team, but the surgical team had experience in both on-pump and off-pump surgery.

The clinical endpoints were the first occurrence of a composite of overall death, myocardial infarction (MI), stroke, or repeat revascularization (MACCE), and the total occurrence of each component of MACCE.

The SSI and SSII calculations were performed according to the official algorithm available at www.syntaxscore.com. The calculations of SSI were performed by 2 interventional cardiologists with the angiography available before the first revascularization procedure of each patient and clinical data obtained from the medical records for the calculation of SSII. Coronary lesions were visually estimated and only those scored had a stenosis $\geq 50 \%$ affecting vessels with a diameter $\geq 1.5 \mathrm{~mm}$. To calculate the rSS of the surgical population, the SSI result was analyzed concomitantly with the surgical reports, and the points of the revascularized lesions were subtracted. In the percutaneous population, the calculation of rSS was performed by analyzing the angiography in which the revascularization procedure was performed. Finally, patients were categorized into 3 groups according to the tertiles obtained in each score (1: low, 2: intermediate, and 3: high).

Quantitative variables are presented as median and interquartile range or mean and standard deviation as appropriate. The normality assumption was evaluated using the Kolmogorov-Smirnov test. Categorical variables are presented as percentages and absolute values. Quantitative variables were compared using the Student's t-test or Wilcoxon rank-sum test and categorical variables by the chi-square test. Intraobserver and interobserver agreement for the SSI were performed for 30 angiographies according to the kappa coefficient. For the correlation analysis between SSI and rSS, the Spearman coefficient was used.

The outcomes were evaluated according to the SSI, SSII, and rSS tertiles presented as Kaplan-Meier curves, and the groups were compared by using the log-rank test. Cox-proportional hazards models were used to analyze time to event data adjusting for multiple covariates for the endpoints. Factors adjusted in the Cox-proportional hazards models include age, sex, diabetes, ejection fraction, SYNTAX I, SYNTAX II, residual SYNTAX, low-density lipoprotein, peripheral artery disease, chronic obstructive pulmonary disease, left-main disease, 3-vessel disease, and smoking history. The interaction of sex, number of diseased vessels, diabetes, renal function, ejection fraction, and tertiles of SYNTAX scores I, II, and residual was tested using Cox-proportional hazards models with interaction terms.

Receiver operating characteristic (ROC) curves were performed to assess the accuracy of SSI, SSII, and rSS for MACCE and overall death by calculating areas under the curves (AUC).

An exploratory analysis to identify independent predictors of MACCE and death was performed using clinical, angiographic, and laboratory variables. Variables with $P<.2$ values in univariate tests were tested by Cox regression with the backward stepwise method, and only those with a $P<.05$ variables remained in the final model. 
The tests were performed with significance levels of $5 \%$. Statistical analyses were performed using SPSS $21.0\left(\mathrm{IBM}{ }^{\circledR}\right)$ software for Macintosh.

\section{Results}

In the period from 2008 to 2018, 969 patients underwent a revascularization procedure. Of these, 410 underwent $\mathrm{PCl}$ and 559 underwent CABG. The median follow-up of our sample was 5 years (Figure 1). A cohort flow diagram is presented in the supplement eFigure 1.

In the CABG sample, the SSI median was 23 (17-29.5), SSII median 25.4 (19.2-32.8), and rSS median 2 (06.5). A LIMA to LAD was present in $97.7 \%$, and $12.3 \%$ received an additional arterial graft, $51.3 \%$ of patients were diabetic, and complete revascularization was achieved in $40.1 \%$ (Table 1). MACCE occurred in 87 (15.6\%), death in 36 (6.4\%), Ml in 31 (5.5\%), repeat revascularization in 21 (3.8\%), and stroke in 10 (1.8\%) patients (Table 2).

In the PCl group, the SSI median was 14 (10-19.1), SSII median 28.7 (23-34.2), and rSS median 4.7 (0-9). DES was used in $37.1 \%$ of patients and $60.2 \%$ had diabetes; complete revascularization was achieved in $25.9 \%$ (Table 1). MACCE occurred in 87 (21.2\%), death in 36 (8.8\%), MI in $28(6.8 \%)$, repeat revascularization in $47(11.5 \%)$, and stroke in $13(3.2 \%)$ patients (Table 2). 
Table 1

Baseline characteristics of CABG and PCl samples.

\begin{tabular}{|llll|}
\hline Variables & PCI population - 410 & CABG - 559 & $P$-value \\
\hline Age (IQR) & $61(54-67)$ & $63(57-69)$ & $<.001$ \\
\hline Male sex (\%) & $258(62.9)$ & $398(71.2)$ & $<.001$ \\
\hline Hypertension (\%) & $331(80.9)$ & $444(79.4)$ & .564 \\
\hline Diabetes (\%) & $247(60.2)$ & $287(51.3)$ & .006 \\
\hline Smoke history (\%) & $179(43.7)$ & $308(55.1)$ & $<.001$ \\
\hline EF (IQR) & $62,5(58-69)$ & $60(51-64)$ & $<.001$ \\
\hline SYNTAX score I (IQR) & $14(10-19.1)$ & $23(17-29.5)$ & $<.001$ \\
\hline Residual SYNTAX score (IQR) & $4,7(0-9)$ & $2(0-6,5)$ & $<.001$ \\
\hline SYNTAX score II (IQR) & $28,7(23-34.2)$ & $25,4(19.2-32.8)$ & $<.001$ \\
\hline PAD (\%) & $22(5.4)$ & $67(12)$ & $<.001$ \\
\hline COPD (\%) & $6(1.5)$ & $27(4.8)$ & .004 \\
\hline GFR (IQR) & $67(57-80)$ & $69(58-79)$ & .514 \\
\hline LDL (IQR) & $117(89-145)$ & $106(83-134)$ & .002 \\
\hline Aspirin / Clopidogrel (\%) & $406(99)$ & $553(98.9 \%)$ & .882 \\
\hline Statin (\%) & $400(97.6)$ & $553(98.9 \%)$ & .099 \\
\hline Three-vessel disease (\%) & $215(51)$ & $220(39.4)$ & $<.001$ \\
\hline Left-main (\%) & $15(3.7)$ & $116(20.8)$ & $<.001$ \\
\hline Complete revascularization (\%) & $106(25.9)$ & $224(40.1)$ & $<.001$ \\
\hline Drug eluting stent (\%) & $152(37.1)$ & $523(57.8)$ & - \\
\hline On-pump CABG (\%) & N.A & $59(12.3)$ & - \\
\hline Left internal thoracic artery (\%) & N.A & & - \\
\hline Second arterial graft (\%) & N.A & & - \\
\hline Number of grafts (SD) & N.A & & $-64)$ \\
\hline
\end{tabular}


Table 2

Event rate in $\mathrm{CABG}$ and $\mathrm{PCl}$.

\begin{tabular}{|llll|}
\hline Events & CABG $(\mathbf{n = 5 5 9 )}$ & PCI $(\mathbf{n = 4 1 0 )}$ & $P$-value \\
\hline MACCE, $\mathrm{n}(\%)$ & $87(15.6)$ & $87(21.2)$ & .008 \\
\hline Death, $\mathrm{n}(\%)$ & $36(6.4)$ & $36(8.8)$ & .195 \\
\hline MI, $\mathrm{n}(\%)$ & $31(5.5)$ & $28(6.8)$ & .333 \\
\hline Revasc, $\mathrm{n}(\%)$ & $21(3.8)$ & $47(11.5)$ & $<.001$ \\
\hline Stroke, $\mathrm{n}(\%)$ & $10(1.8)$ & $13(3.2)$ & .174 \\
\hline $\begin{array}{l}\text { MACCE: } \text { major adverse cardiac and cerebrovascular events; } \text { MI: myocardial infarction; Revasc: Repeat } \\
\text { revascularization. }\end{array}$
\end{tabular}

Table 3: Univariate and Multivariate Cox Regression for MACCE and Death. 


\begin{tabular}{|c|c|c|c|c|c|c|c|c|}
\hline \multirow{3}{*}{ Variables } & \multicolumn{4}{|l|}{ MACCE } & \multicolumn{4}{|l|}{ Death } \\
\hline & \multicolumn{2}{|c|}{ Univariate analysis } & \multicolumn{6}{|c|}{ Multivariate analysis } \\
\hline & $\begin{array}{l}\mathrm{HR}(\mathrm{Cl} \\
95 \%)\end{array}$ & $\begin{array}{l}P \\
\text { value }\end{array}$ & $\begin{array}{l}\mathrm{HR} \\
(95 \% \mathrm{Cl})\end{array}$ & $\begin{array}{l}\mathrm{p} \\
\text { value }\end{array}$ & $\begin{array}{l}\mathrm{HR}(\mathrm{Cl} \\
95 \%)\end{array}$ & $\begin{array}{l}P \\
\text { value }\end{array}$ & $\begin{array}{l}\mathrm{HR} \\
(95 \% \mathrm{Cl})\end{array}$ & $\begin{array}{l}P \\
\text { value }\end{array}$ \\
\hline HTN & $\begin{array}{l}1.416 \\
(0.939- \\
2.135)\end{array}$ & .097 & & & $\begin{array}{l}1.591 \\
(0.816- \\
3.102)\end{array}$ & .173 & & \\
\hline DM & $\begin{array}{l}1.272 \\
(0.938- \\
1.725)\end{array}$ & .121 & & & $\begin{array}{l}1.574 \\
(0.964- \\
2.569)\end{array}$ & .070 & & \\
\hline $\begin{array}{l}\text { Smoke } \\
\text { history }\end{array}$ & $\begin{array}{l}0.861 \\
(0.640- \\
1.160)\end{array}$ & .325 & & & $\begin{array}{l}1.061 \\
(0.771- \\
1.460)\end{array}$ & .716 & & \\
\hline $\begin{array}{l}\text { SSI (each } \\
\text { point)* }\end{array}$ & $\begin{array}{l}1.014 \\
(0.998- \\
1.030)\end{array}$ & .089 & & & $\begin{array}{l}1.010 \\
(0.985- \\
1.036)\end{array}$ & .449 & & \\
\hline $\begin{array}{l}\text { rSS (each } \\
\text { point)* }\end{array}$ & $\begin{array}{l}1.043 \\
(1.018- \\
1.067)\end{array}$ & .001 & $\begin{array}{l}1.042 \\
(1.017- \\
1.067)\end{array}$ & 0.001 & $\begin{array}{l}1.013 \\
(0.973- \\
1.055)\end{array}$ & .534 & & \\
\hline $\begin{array}{l}\text { Age (each } \\
\text { point)* }\end{array}$ & $\begin{array}{l}1.010 \\
(0.993- \\
1.027)\end{array}$ & .243 & & & $\begin{array}{l}1.022 \\
(0.995- \\
1.050)\end{array}$ & .110 & & \\
\hline $\begin{array}{l}\text { Three- } \\
\text { vessel }\end{array}$ & $\begin{array}{l}1.119 \\
(0.831- \\
1.507)\end{array}$ & .460 & & & $\begin{array}{l}1.117 \\
(0.703- \\
1.774)\end{array}$ & .640 & & \\
\hline PAD & $\begin{array}{l}1.079 \\
(0.662- \\
1.757)\end{array}$ & .761 & & & $\begin{array}{l}1.527 \\
(0.783- \\
2.978)\end{array}$ & .214 & & \\
\hline COPD & $\begin{array}{l}0.299 \\
(0.074- \\
1.206)\end{array}$ & .090 & & & $\begin{array}{l}0.047 \\
(<0.001- \\
10.033)\end{array}$ & .264 & & \\
\hline $\begin{array}{l}\text { GFR } \\
\text { (each } \\
\text { point)* }\end{array}$ & $\begin{array}{l}0.992 \\
(0.983- \\
1.000)\end{array}$ & .060 & & & $\begin{array}{l}0.984 \\
(0.971- \\
0.998)\end{array}$ & .025 & $\begin{array}{l}0.987 \\
(0.973- \\
1.001)\end{array}$ & .029 \\
\hline $\begin{array}{l}\text { LDL (each } \\
\text { point)* }\end{array}$ & $\begin{array}{l}0.998 \\
(0.994- \\
1.001)\end{array}$ & .193 & & & $\begin{array}{l}0.998 \\
(0.992- \\
1.003)\end{array}$ & .403 & & \\
\hline $\begin{array}{l}\text { EF (each } \\
\text { point)* }\end{array}$ & $\begin{array}{l}0.973 \\
(0.959- \\
0.987)\end{array}$ & $<.001$ & $\begin{array}{l}0.973 \\
(0.960- \\
0.987)\end{array}$ & $<0.001$ & $\begin{array}{l}0.972 \\
(0.951- \\
0.993)\end{array}$ & .010 & $\begin{array}{l}0.972 \\
(0.951- \\
0.993)\end{array}$ & .009 \\
\hline $\begin{array}{l}\text { Female } \\
\text { sex }\end{array}$ & $\begin{array}{l}1.153 \\
(0.855- \\
1.554)\end{array}$ & .350 & & & $\begin{array}{l}0.865 \\
(0.538- \\
1.389)\end{array}$ & .548 & & \\
\hline
\end{tabular}


*Variables were analyzed continuously. COPD: chronic obstructive pulmonary disease; DM: diabetes mellitus; GFR: Glomerular filtration rate; HTN: hypertension; LDL: low-density lipoprotein; MACCE: major cardiovascular and cerebrovascular events; PAD: peripheral artery disease, NA: not available.

Before stratification according to SYNTAX scores, a comparison between CABG and PCI whole cohorts found a significant lower difference for MACCE (15.6\% versus $21.2 \%, P$ log-rank $=.008$; adjusted hazard ratio, $1.984 ; 95 \% \mathrm{Cl}, 1.134-3.470 ; P=.016)$ and repeat revascularization (3.8\% versus $11.5 \%, P$ log-rank $<.001$; adjusted hazard ratio, $4.356 ; 95 \% \mathrm{Cl}, 1.749-10.860 ; P=.002$; respectively) in the surgical group. The death rate was similar between PCl versus CABG (8.8\% versus $6.4 \%$, Plog-rank $=.195)$ (Figure 1 and Table 2).

\section{SYNTAX score I}

Analyses of intraobserver (kappa:0.604, 95\% Cl, 0.269-0.787, $P<.001$ ) and interobserver variability (kappa:0.660, 95\% Cl, 0.390-0.825, $P<.001)$ for the SSI were at least moderate. The SSI tertiles obtained were a low SSI $\leq 15$ ( $n=328)$, intermediate SSI 15-24 ( $n=340)$, and high SSI >24 (301). CABG sample had 89,214 , and 256 patients in low, intermediate, and high SSI tertiles, respectively. In PCI, 239, 126, and 45 patients were found in low, intermediate, and high SSI tertiles.

The composite outcome in the lower tertile of SSI was not significantly different between CABG and PCI: $12(13.5 \%)$ versus $43(18 \%), P=.136$. The only significant difference found was for the individual analysis of repeat revascularization: $\mathrm{n}=3(3.4 \%)$ in $\mathrm{CABG}$ versus $27(11.3 \%)$ in $\mathrm{PCl}(P$ log-rank=.021; adjusted hazard ratio, $7.071 ; \mathrm{Cl} 95 \%, 1.367-36.561 ; P=.020)$. No difference was found in the individual analysis of death $(P=.227)$, myocardial infarction $(P=.637)$, or stroke $(P=.222)$ (eTable 1 in the supplement).

In the intermediate SSI tertile, the primary outcome was significantly different between CABG and PCI, with an event rate of $25(11.7 \%)$ in CABG versus 29 in $\mathrm{PCl}(23 \%)$ ( $P$ log-rank=.002; adjusted hazard ratio, $2.704 ; 95 \% \mathrm{Cl}, 0.967-7.563 ; P=.58)$. There was a difference for myocardial infarction: $\mathrm{n}=8(3.7 \%)$ in $\mathrm{CABG}$ versus $\mathrm{n}=15$ (11.9\%) (log-rank, $P=.002$; adjusted hazard ratio, 3.131; $95 \% \mathrm{Cl}, 0.556-17.637 ; P=.196)$. Repeat revascularization rate was also higher in PCl: $n=7$ (3.3\%) in CABG versus $n=12(9.5 \%)$ in $\mathrm{PCl}(\log$ rank, $P=.008$; adjusted hazard ratio, $3.061 ; 95 \% \mathrm{Cl}, 0.587-15.963 ; P=.184)$. No difference was found in the individual analysis of death $(P=.201)$ or stroke $(P=.419)$ (eTable 1 in the supplement).

MACCE rate was significantly different between CABG and PCI in the higher tertile of SSI: $n=50(19.5 \%)$ in CABG versus $\mathrm{n}=15$ (33.3\%) in $\mathrm{PCl}(P$ log-rank $=.016$; adjusted hazard ratio, 5.157; 95\% Cl, 1.698-15.659; $P=.004)$. Repeat revascularization was higher in $\mathrm{PCl}, \mathrm{n}=9(20 \%)$ versus $\mathrm{CABG}, \mathrm{n}=10$ (3.9\%) (log rank $P<.001$; adjusted hazard ratio, $89.909 ; 95 \% \mathrm{Cl}, 11.672-692.570 ; P<.001)$. Stroke rate was also significantly different: $\mathrm{n}=6(2.3 \%)$ in $\mathrm{CABG}$ and $5(11.1 \%)$ in $\mathrm{PCl}$ (log rank $P=.004$; adjusted $\mathrm{HR}, 10.132 ; 95 \% \mathrm{Cl}, 0.592-$ 
179.726; $P=.110)$. No difference was found in the individual analysis of death $(P=.325)$ or myocardial infarction ( $P=.986)$ (eTable 1 in the supplement).

\section{SYNTAX score II}

The SSII tertiles obtained were a low SSII $\leq 23(n=330)$, intermediate SSII 23-31.3 $(n=320)$, and high SSII $>31.3$ (319). CABG group had 89, 214, and 256 patients in low, intermediate, and high SSIl tertiles, respectively. In PCl, 239, 126, and 45 patients were in low, intermediate, and high SSIl tertiles.

The composite outcome in the lower tertile of SSII was not significantly different between CABG and PCl: $26(11.4 \%)$ versus $19(18.6 \%)(P=.055)$. Repeat revascularization was higher in $\mathrm{PCl}$ : $\mathrm{n}=3(1.3 \%)$ events in CABG versus $\mathrm{n}=27(11.3 \%)$ in $\mathrm{PCl}(P$ log-rank<.001; adjusted hazard ratio, 5.402; 95\% Cl, 0.472-61.822; $P=.175)$. No difference was found in the individual analysis of death $(P=.113), \mathrm{MI}(P=.799)$, and stroke $(P=.644)$ (eTable 2 in the supplement).

In the intermediate SSII tertile, the primary outcome was not significantly different between CABG and PCI with an event rate of 31 (17.8\%) in CABG versus 28 (19.2\%) in $\mathrm{PCl}(P=.568)$. No difference was found for death $(P=.295), \mathrm{MI}(P=.329)$, repeat revascularization $(P=.156)$, or stroke, $\mathrm{n}=4(P=0.773)$ (eTable 2 in the supplement).

MACCE rate was statistically similar between CABG and PCI in the higher tertile of SSII: $n=30(19.1 \%)$ in CABG versus $\mathrm{n}=40(24.7 \%)$ in $\mathrm{PCl}(P=.132)$. A significant difference was found only for repeat revascularization: $n=7(4.5 \%)$ in CABG versus $n=23(14.2 \%)$ in $\mathrm{PCl}(P$ log-rank=.002; adjusted hazard ratio, $12.607 ; 95 \% \mathrm{Cl}, 2.848-55.800 ; P=.001)$. There was no difference in the individual analysis of death $(P=.172)$, myocardial infarction $(P=.972)$, or stroke $(P=.234)$ (eTable 2 in the supplement).

\section{Residual SYNTAX score}

A correlation evaluation between SSI and rSS was performed for both surgical procedures. A moderate correlation was found after $\mathrm{PCl}(\mathrm{R}=0.686, P<.001)$, but it was weak after $\mathrm{CABG}(\mathrm{R}=0.200, P<.001)$.

Residual SYNTAX score tertiles were low rSS $=0(n=330)$, intermediate rSS 0-6 $(n=337)$, and high $r S S>6$ (302). CABG group had 224, 195, and 140 patients in low, intermediate, and high SSII tertiles, respectively. In $\mathrm{PCl}, 106,142$, and 162 patients were in low, intermediate, and high SSII tertiles.

MACCE rate of low rSS tertile was $\mathrm{n}=26(11.6 \%)$ in $\mathrm{CABG}$ and $\mathrm{n}=14(13.2 \%)$ in $\mathrm{PCl}(P=0.533)$. No difference was found in the individual analysis of death $(P=.795)$, $\mathrm{MI}(P=.673)$, repeat revascularization $(P=.275)$, or stroke $(P=0.407)$ (eTable 3 in the supplement).

Intermediate rSS tertile had a primary outcome rate not significantly different between CABG and PCl: $\mathrm{n}=33(16.9 \%)$ in $\mathrm{CABG}$ versus $\mathrm{n}=35(24.6 \%)$ in $\mathrm{PCl}(P=.066)$. The only difference found was for repeat revascularization: $\mathrm{n}=8$ (4.1\%) in CABG versus $\mathrm{n}=22$ (15.5\%) in $\mathrm{PCl}$ (log-rank, $P<.001$; adjusted hazard ratio, 
6.008; $95 \% \mathrm{Cl}, 1.435-25,152 ; P=.014)$. No difference occurred for death $(P=.269)$, $\mathrm{Ml}(P=.663)$, or stroke $(P=.751)$ (eTable 3 in the supplement).

In the higher tertile of rSS, the MACCE rate was statistically similar between groups: $n=28(20 \%)$ in CABG versus $\mathrm{n}=38(23.5 \%)$ in $\mathrm{PCl}(P=.291)$. A significant difference was found for repeat revascularization: $\mathrm{n}=7$ $(5 \%)$ in $\mathrm{CABG}$ versus $\mathrm{n}=21$ (13\%) in $\mathrm{PCl}(P$ log-rank $=.012$; adjusted hazard ratio, $12.604 ; 95 \% \mathrm{Cl}, 2.524-$ $62.949 ; P=.002)$. No difference occurred in the analysis of death $(P=.497)$, $\mathrm{Ml}(P=.621)$, or stroke $(P=.571)$ (eTable 3 in the supplement).

\section{SYNTAX scores accuracy, subgroup, and multivariate analysis}

Independent predictors for MACCE in our sample were evaluated in a model testing each component of SSII with rSS, SSI, and other baseline variables. In this sample, the rSS as a continuous variable was an independent predictor for MACCE (hazard ratio, $1.042 ; 95 \% \mathrm{Cl}, 1.017-1.067 ; P=.001$ ) as was EF. For the analysis of death, EF and GFR were the only independent predictors (Table 3). In the subgroup analysis, there was no interaction among the tertiles of the 3 SYNTAX scores and the revascularization procedure, but an interaction for the reduction of MACCE in CABG compared with $\mathrm{PCl}$ was found for diabetes $(P=.034)$ (Figure 2).

ROC curves were built to examine the accuracy for MACCE and death in our sample. SSI AUC was 0.540 (95\% Cl, 0.494-0.586; $P=.095)$ for MACCE and 0.592 (95\% Cl, 0.448-0.590; $P=.592)$ for death. SSII AUC was 0.567 (95\% Cl, 0.522-0.613; $P=.005)$ for MACCE and 0.609 (95\% Cl, 0.541-0.677; $P=.002)$ for death. RSS AUC was $0.581(95 \% \mathrm{Cl}, 0.535-0.627, P=.001)$ for MACCE and $0.528(95 \% \mathrm{Cl}, 0.462-0.595 ; P=.034)$ for death.

\section{Discussion}

To the best of our knowledge, this is the first study to simultaneously analyze 3 SYNTAX scores in patients undergoing different revascularization procedures. The application of the 3 scores found a higher rate of MACCE and repeat revascularization in $\mathrm{PCl}$, but there was no statistical difference for mortality between surgical and percutaneous interventions. Furthermore, the incomplete revascularization graded through the rSS was an independent predictor of the composite outcome (MACCE) in both interventions.

MACCE lower rate in CABG compared with that in $\mathrm{PCl}$ was mostly driven by a reduction in the repeat revascularization rate, which has been associated in some studies with a worse prognosis. ${ }^{15,16}$ The higher composite event rate in $\mathrm{PCl}$ may partially be explained by stent restenosis but also due to a higher level of incomplete revascularization in patients with greater anatomical complexity and atherosclerotic burden. In this regard, we found a higher correlation of SSI and rSS in PCI and no difference for MACCE in the lower tertile of SSI; with the repeat revascularization rate increasing especially in the higher SSI tertile undergoing percutaneous treatment indicating that the SSI has value for event prediction in PCI. Even 
though SSI was higher in CABG, surgical revascularization was more frequently complete as it is more influenced by the quality of the distal vessel than the anatomic complexity analyzed through SSI.

Incomplete revascularization evaluated by the rSS was a decisive factor for the worse prognosis of the disease. In fact, in a recent meta-analysis, incomplete revascularization was associated with higher rates of events, especially acute myocardial infarction and repeated revascularization. ${ }^{14}$ In our data, the incompleteness of myocardial revascularization assessed and graded by the rSS was associated with outcomes even in a population without a high level of residual non-revascularized disease, highlighting the importance of complete revascularization. Even though no interaction occurred between the benefit of CABG and the tertile of rSS, our results suggest that a complete $\mathrm{PCl}$ has a similar event rate compared to CABG.

To date, no score has been shown to accurately predict mortality in patients with stable CAD undergoing a revascularization procedure. This study demonstrates that none of the SYNTAX scores were accurately associated with survival, and regardless of the revascularization procedure of choice, there is no difference in death rate. Of note, the SYNTAX trial found a survival difference in favor of CABG in the higher tertile of its sample; however, our sample has a lower disease complexity, which may explain the similar survival rates in the procedures and, in fact, most likely representing the large majority of patients with CAD. ${ }^{3}$

Some considerations must be highlighted in understanding the results of the present study. It is a registrybased study with patients from a single quaternary hospital, and patients were referred for surgery or percutaneous treatment; therefore, this sample represents real-world data. Because it was an observational study, we did not have access to the reasons leading to each treatment strategy indication (PCl or $\mathrm{CABG}$ ). Also, the use of bare metal or DES was at the discretion of the interventionist or the availability of DES, and it could influence the rate of stent restenosis and the repeat revascularization rate.

\section{Conclusion}

Surgical revascularization resulted in a more complete revascularization and lower rates of major cardiac or cerebrovascular events in a long-term follow-up. Also, grading the incompleteness of revascularization through the residual SYNTAX score identified a higher event rate, suggesting that complete revascularization is associated with a better prognosis.

\section{Abbreviations}

AUC: area under the curve

BMS: bare metal stent

CABG: coronary artery bypass grafting 
COPD: chronic obstructive pulmonary disease

CrCL: creatinine clearance

DES: drug eluting stent

EF: Ejection fraction

GFR: glomerular filtration rate

HTN: hypertension

LAD: Left anterior descending

LDL: low density lipoprotein

LIMA: Left internal mammary artery

PAD: peripheral artery disease

PCl: percutaneous coronary intervention

SSI: SYNTAX score I

SSII: SYNTAX score II

ROC: Receiver operating characteristic

rSS: residual SYNTAX score

\section{Declarations}

\section{Ethics approval and consent to participate}

The present study was approved by the Ethics Committee of the CAPPesq REGISTRY ONLINE: 8595/2012 - CAAE: 00686812.3.0000.0068, in Brazil, and adhered to the Declaration of Helsinki. Additionally, written informed consent was acquired from the patients or the patient's relatives.

\section{Consent for publication}

All authors read and approved the final manuscript for publication.

\section{Availability of data and materials}

Please contact the corresponding author for data requests.

\section{Competing interests}


The authors declare that they have no competing interests.

\section{Funding}

Financial support for the present study was provided in part by a research grant from Zerbini Foundation and also by Fundação de Amparo à Pesquisa do Estado de São Paulo (FAPESP) Number 2011/20876-2.

\section{Authors' contributions}

Contribution of each author: EBM: concept and design of the manuscript; analysis and interpretation of data; WH: conception and design of this study and final approval of the manuscript; DLB: conception of this trial; TLS: interpretation of data; EGL: acquisition, analysis, and interpretation of data; PCR: drafting the article or revising it; PRS: acquisition and analysis of data; CLG: analysis of data; JPP: drafting the article or revising it; DVB: analysis of data; JAFR: design of this study and final approval of the submitted manuscript; RKF: final approval of the submitted manuscript.

\section{Acknowledgments}

The support for the present study was provided in part by the Zerbini Foundation, São Paulo, Brazil, and Ann Conti Morcos of MorcosMedia provided medical writing support during the preparation of this paper. The authors are solely responsible for the design and conduct of this study; all study analyses, the drafting and editing of the paper, and its final contents.

\section{References}

1. Sianos G, Morel MA, Kappetein AP, Morice MC, Colombo A, Dawkins K, et al. The SYNTAX Score: an angiographic tool grading the complexity of coronary artery disease. Eurolntervention. 2005;1(2):21927.

2. Serruys PW, Morice MC, Kappetein AP, Colombo A, Holmes DR, Mack MJ, et al. Percutaneous coronary intervention versus coronary-artery bypass grafting for severe coronary artery disease. $N$ Engl J Med. 2009;360(10):961-72.

3. Caixeta A, Genereux P, Palmerini T, Lansky AJ, Mehran R, Dangas GD, et al. Prognostic utility of the SYNTAX score in patients with single versus multivessel disease undergoing percutaneous coronary intervention (from the Acute Catheterization and Urgent Intervention Triage StrategY [ACUITY] trial). Am J Cardiol. 2014;113(2):203-10.

4. Mohr FW, Morice MC, Kappetein AP, Feldman TE, Stahle E, Colombo A, et al. Coronary artery bypass graft surgery versus percutaneous coronary intervention in patients with three-vessel disease and left main coronary disease: 5-year follow-up of the randomised, clinical SYNTAX trial. Lancet. 2013;381(9867):629-38.

5. Kang J, Han JK, Kang DY, Zheng C, Yang HM, Park KW, et al. SYNTAX score and SYNTAX score II can predict the clinical outcomes of patients with left main and/or 3-vessel disease undergoing 
percutaneous coronary intervention in the contemporary cobalt-chromium everolimus-eluting stent era. Korean Circ J. 2019.

6. Capodanno D, Tamburino C. Integrating the Synergy between percutaneous coronary intervention with Taxus and Cardiac Surgery (SYNTAX) score into practice: use, pitfalls, and new directions. Am Heart J. 2011;161(3):462-70.

7. Mohr FW, Rastan AJ, Serruys PW, Kappetein AP, Holmes DR, Pomar JL, et al. Complex coronary anatomy in coronary artery bypass graft surgery: impact of complex coronary anatomy in modern bypass surgery? Lessons learned from the SYNTAX trial after two years. J Thorac Cardiovasc Surg. 2011;141(1):130-40.

8. Lemesle G, Bonello L, de Labriolle A, Steinberg DH, Roy P, Pinto Slottow TL, et al. Prognostic value of the Syntax score in patients undergoing coronary artery bypass grafting for three-vessel coronary artery disease. Catheter Cardiovasc Interv. 2009;73(5):612-7.

9. Birim O, van Gameren M, Bogers AJ, Serruys PW, Mohr FW, Kappetein AP. Complexity of coronary vasculature predicts the outcome of surgery for left main disease. Ann Thorac Surg. 2009;87(4):1097-104; discussion 104-5.

10. Carnero-Alcazar M, Maroto Castellanos LC, Silva Guisasola JA, Cobiella Carnicer J, Alswies A, Fuentes Ferrer ME, et al. SYNTAX Score is associated with worse outcomes after off-pump coronary artery bypass grafting surgery for three-vessel or left main complex coronary disease. J Thorac Cardiovasc Surg. 2011;142(3):e123-32.

11. Bundhun PK, Yanamala CM, Huang F. Percutaneous coronary intervention, coronary artery bypass surgery and the SYNTAX score: A systematic review and meta-analysis. Sci Rep. 2017;7:43801.

12. Farooq V, van Klaveren D, Steyerberg EW, Meliga E, Vergouwe Y, Chieffo A, et al. Anatomical and clinical characteristics to guide decision making between coronary artery bypass surgery and percutaneous coronary intervention for individual patients: development and validation of SYNTAX score II. Lancet. 2013;381(9867):639-50.

13. Garcia S, Sandoval Y, Roukoz H, Adabag S, Canoniero M, Yannopoulos D, et al. Outcomes after complete versus incomplete revascularization of patients with multivessel coronary artery disease: a meta-analysis of 89,883 patients enrolled in randomized clinical trials and observational studies. $J$ Am Coll Cardiol. 2013;62(16):1421-31.

14. Genereux P, Palmerini T, Caixeta A, Rosner G, Green P, Dressler O, et al. Quantification and impact of untreated coronary artery disease after percutaneous coronary intervention: the residual SYNTAX (Synergy Between PCI with Taxus and Cardiac Surgery) score. J Am Coll Cardiol. 2012;59(24):216574.

15. Giustino G, Serruys PW, Sabik JF, 3rd, Mehran R, Maehara A, Puskas JD, et al. Mortality after repeat revascularization following $\mathrm{PCI}$ or $\mathrm{CABG}$ for left main disease: The EXCEL Trial. JACC Cardiovasc Interv. 2020;13(3):375-87.

16. Parasca CA, Head SJ, Milojevic M, Mack MJ, Serruys PW, Morice MC, et al. Incidence, characteristics, predictors, and outcomes of repeat revascularization after percutaneous coronary intervention and 
coronary artery Bypass grafting: The SYNTAX Trial at 5 Years. JACC Cardiovasc Interv. 2016;9(24):2493-507.

Figures
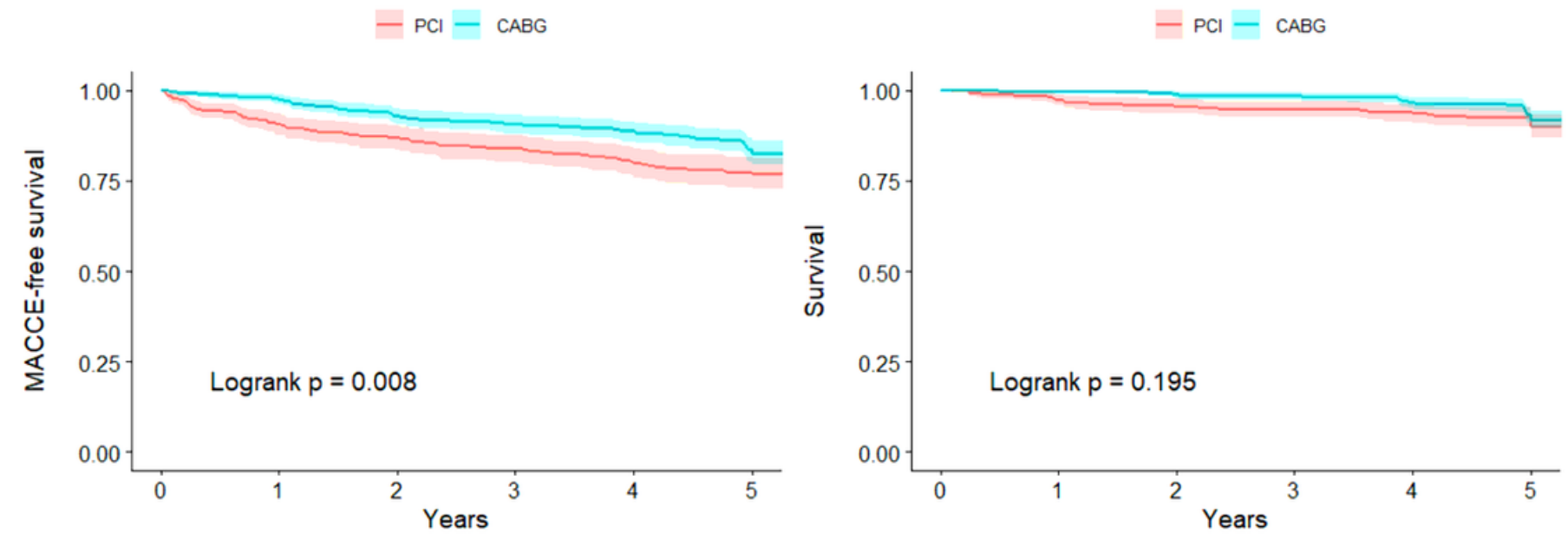

\begin{tabular}{|c|c|c|c|c|c|}
\hline \multicolumn{6}{|c|}{ Number at risk } \\
\hline $\mathrm{PCl}-410$ & 356 & 326 & 306 & 272 & 237 \\
\hline CABG 559 & 530 & 500 & 468 & 422 & 317 \\
\hline 0 & 1 & 2 & 3 & 4 & 5 \\
\hline
\end{tabular}

Number at risk

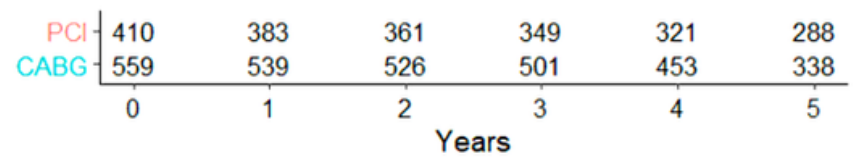

\section{Figure 1}

Kaplan-Meier curves showing combined events (MACCE) and death. CABG: Coronary artery bypass grafting, MACCE: major adverse cardiovascular and cerebrovascular events, PCl: percutaneous coronary intervention. 


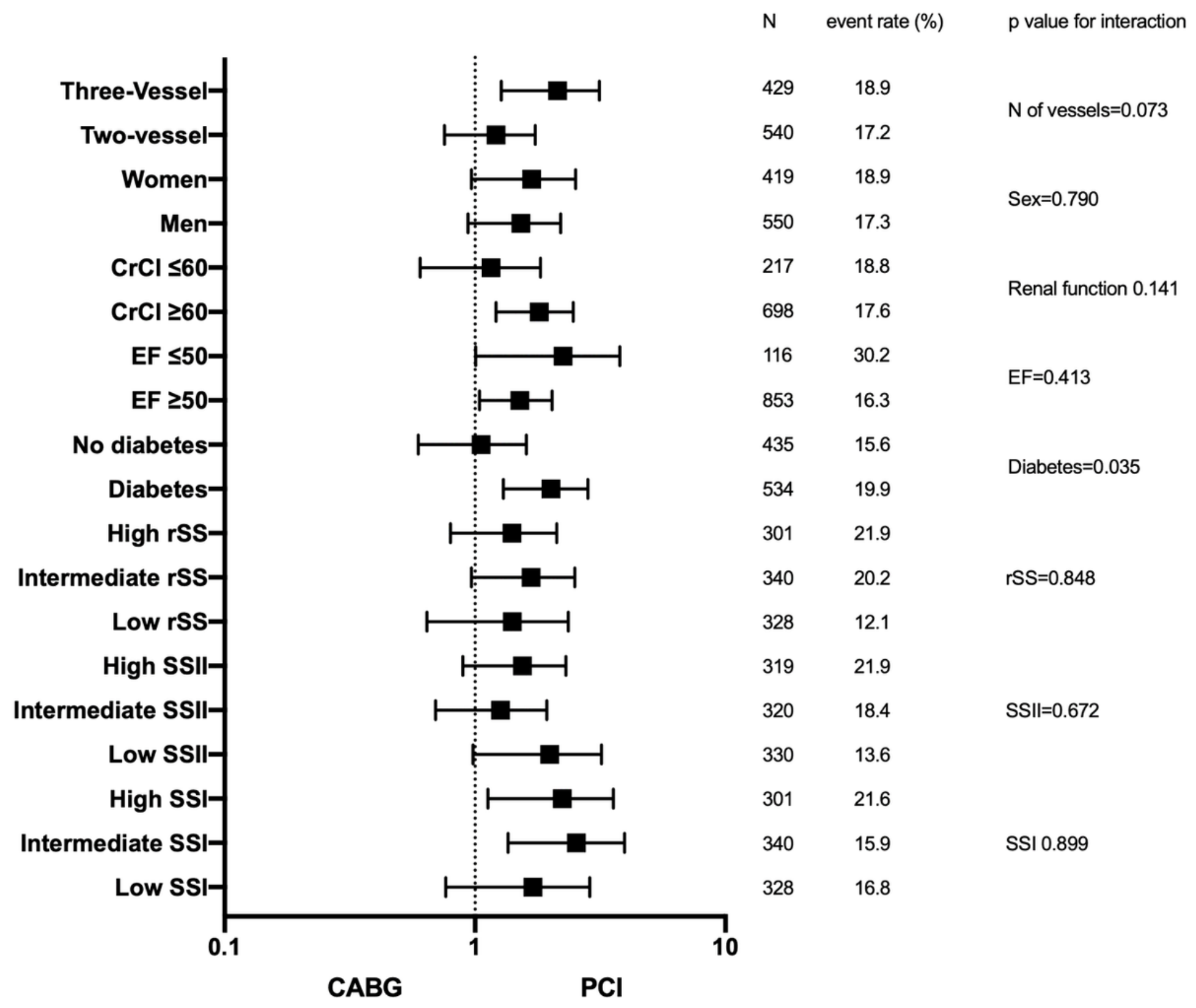

Figure 2

Subgroup analysis for MACCE. CABG: coronary artery bypass grafting; $\mathrm{CrCl}$ : creatine clearance; $\mathrm{EF}$ : ejection fraction; MACCE: Major adverse cardiovascular and cerebrovascular events; PCI: percutaneous coronary intervention; SSI: SYNTAX score I; SSII: SYNTAX score II; rSS: residual SYNTAX score.

\section{Supplementary Files}

This is a list of supplementary files associated with this preprint. Click to download.

- supplementIJCT.docx 